\title{
EARLY FRACTURE OF A PLASMA CUP CERAMIC LINER: A CASE REPORT AND SURFACE ANALYSIS
}

\author{
Jiri Gallo $^{\mathrm{a} *}$, Todd Stewart ${ }^{\mathrm{b}}$, Radek Novotny ${ }^{\mathrm{c}}$, Jan Dusza ${ }^{\mathrm{d}}$, Dusan Galusek ${ }^{\mathrm{e}}$
}

\author{
a Department of Orthopaedics, Teaching Hospital and Faculty of Medicine and Dentistry, Palacky University, I. P. Pavlova 6, \\ Olomouc 775 20, Czech Republic \\ ${ }^{b}$ Institute of Medical and Biological Engineering, School of Mechanical Engineering University of Leeds, United \\ Kingdom \\ c Department of Microscopy Methods, Faculty of Medicine and Dentistry, Palacky University, Czech Republic \\ d Institute of Material Research, Slovak Academy of Sciences, Kosice, Slovak Republic \\ e Joint Glass Centre of the IIC SAS, TnUAD and RONA, Trencin, Slovak Republic \\ e-mail:jiri.gallo@volny.cz
}

Received: September 18, 2007; Accepted: October 15, 2007

Key words: Total hip arthroplasty/Ceramic liner fracture/Early complications/Alumina-on-alumina/Insert fracture

Background: Ceramic surfaces offer excellent tribological properties and for this reason are frequently used in younger patients with osteoarthritis of the hip. However, they may fracture easily owing to low tolerance to tensile and impact stresses in particular. We report a case of early fracture of a currently available ceramic liner in a 44-year-old woman with revision total hip arthroplasty.

Methods and Results: Scanning electron microscopy and macroscopic fractographic examination were done to elucidate the cause of failure. These showed the fracture started most probably at the inner surface of the cup. Several mechanisms of fracture initiation are discussed in the paper.

Conclusion: This is the first report on early fracture of the Plasma cup ceramic liner in white man. The fracture occurred intraoperatively or early postoperatively while the diagnosis was determined much later despite the patient had experienced sensations of subluxations long time before.

\section{INTRODUCTION}

Alumina-on-alumina ceramic hip prostheses were introduced into the practice of total hip arthroplasty (THA) to reduce periprosthetic osteolysis by significantly reducing the generation of wear debris. Also, ceramic wear particles have much lower biological activity than do polyethylene particles ${ }^{1}$. Current alumina ceramics have excellent tribology characteristics and good resistance to compressive loading; their fatigue limits significantly exceed the stresses induced by daily living activities ${ }^{2}$. Consequently, they are often used in young patients with a higher level of activity and increased motion demands.

Despite advances in manufacturing, alumina ceramics remain a subject of concern due to their hardness and limited fracture toughness, which may predispose them to fracture ${ }^{3-5}$. Ceramic head and liner fractures have been reported, often associated with massive metallosis and exposure of the body to particles of titanium or cobaltchromium alloy from the metallic shell ${ }^{6}$. It was recently found that serum titanium levels may remain elevated for more than 1 year after revision ${ }^{7}$.

In this case report, we present a very early failure of an alumina ceramic liner in a modern total hip arthroplasty. Scanning electron microscopy and macroscopic fractographic analysis were performed, and possible mechanisms of fracture initiation are discussed.

\section{CASE REPORT}

In December 1995, a 37-year-old woman underwent a cementless Anatomique Benoist Girard (ABG) hip arthroplasty (Howmedica, Staines, England) for advanced osteonecrosis of the left femoral head. Throughout the normal course of the surgery and postoperative period the patient was never fully satisfied with the surgery and complained early of instability and intermittent pain. The patient's weight and height were $90 \mathrm{~kg}$ and $168 \mathrm{~cm}$, respectively (body mass index $=31.8$ ).

In January 2002, the patient complained of pain, and periprosthetic osteolysis was observed on x-ray (Fig. 1A). Revision surgery was performed. Interestingly, no sign of impingement of the neck of the stem on the edge of the cup was identified on the polyethylene liner. A type-II ${ }^{8}$ defect was found at the acetabular site, and the region of the major trochanter was largely destroyed by osteolysis, while the diaphyseal bone was uncompromised. After meticulous debridement of the osteolysis and spongioplasty, a hemispherical cup (Plasma cup SC, Aesculap, Tuttlingen, Germany) and press-fit stem (Wagner SL, Centerpulse, Switzerland) were implanted. The outer diameter of the cup was $52 \mathrm{~mm}$; thus, a ceramic liner for a 28-mm-diameter ceramic head was chosen (Biolox Forte, CeramTec, Plochingen, Germany). The hip was confirmed to be stable, with no observed neck-rim impingement in any direction intraoperatively. On radiograph (Fig. 1B), the 
cup was observed to be settled across the Kohler line with an abduction angle of $48^{\circ}$.

As early as 3 months after the revision surgery the patient again complained of pain. Early sepsis was excluded by routine procedures including serological tests and aspiration ${ }^{9}$. Neurological examination excluded neurological disease as a primary source of complaints. One year later the patient presented subluxations of the left hip. Thirty months after the revision surgery, ceramic fragments were apparent on X-ray (Fig. 1C) but were misjudged as ossification. The difficulties with instability and pain increased until October 2005 when squeaking manifested. However, the patient refused revision surgery at that time. Revision surgery was performed in May 2006 when the squeaking noise accompanied each step, and gross dislocation of the ceramic liner was observed on x-ray (Fig. 1D).

Arthrotomy revealed excessive metallosis, and 2 large pieces of ceramic liner and numerous small ceramic fragments (ranging from $1 \mathrm{~mm}$ to $1 \mathrm{~cm}$ ) were retrieved. It was clear when examining the components that the alumina head had been articulating directly against the stable metallic shell. The metallic shell and neck of the femoral stem were damaged but not fractured. The femoral stem was well fixed to the bone tissue; thus, a transfemoral approach was used to extract it. After a meticulous debridement, a cementless threaded cup (Bicon plus; Endoprothetik plus, Switzerland) and Wagner revision stem (Zimmer, USA) were implanted. The bearing surfaces consisted of a polyethylene liner and alumina-ceramic head (Biolox Forte).

\section{Description of the retrieved surfaces}

Following clearing and sterilization, the retrieved damaged ceramic components were coated with gold (approximately $5 \mathrm{~nm}$; Polaron E5100, Polaron, UK). They and the metallic shell were examined using a stereo binocular microscope with a fiber optical light source (JD and DG) and a Tesla BS 340 scanning electron microscope (SEM; RN) (Tesla, Czech Republic).

The retrieved metallic shell was greatly damaged, with almost complete "wear-through" in some places where it was obvious that the ceramic head had been articulating (Fig. 2). An irregular net of grooves was observed, suggesting long-term abrasion.

The ceramic liner was completely destroyed (Fig. 3), and only a part of the original fracture surface was preserved at the time of surgery. The portions of the ceramic liner remaining in the metal shell were greatly damaged, probably by the interposed ceramic debris and impingement by the neck of the stem.

The prosthetic ball was not fractured. However, its surface was seriously damaged by wear and had lost its spherical shape. At the surface of the prosthetic ball, there were signs of contact fatigue, together with pinholes after chipping (Fig. 4).

\section{The probable reason of fracture}

Because the remnants of the ceramic liner retrieved during surgery were severely damaged, assessment of the true cause of failure was very difficult. Based on the mac-

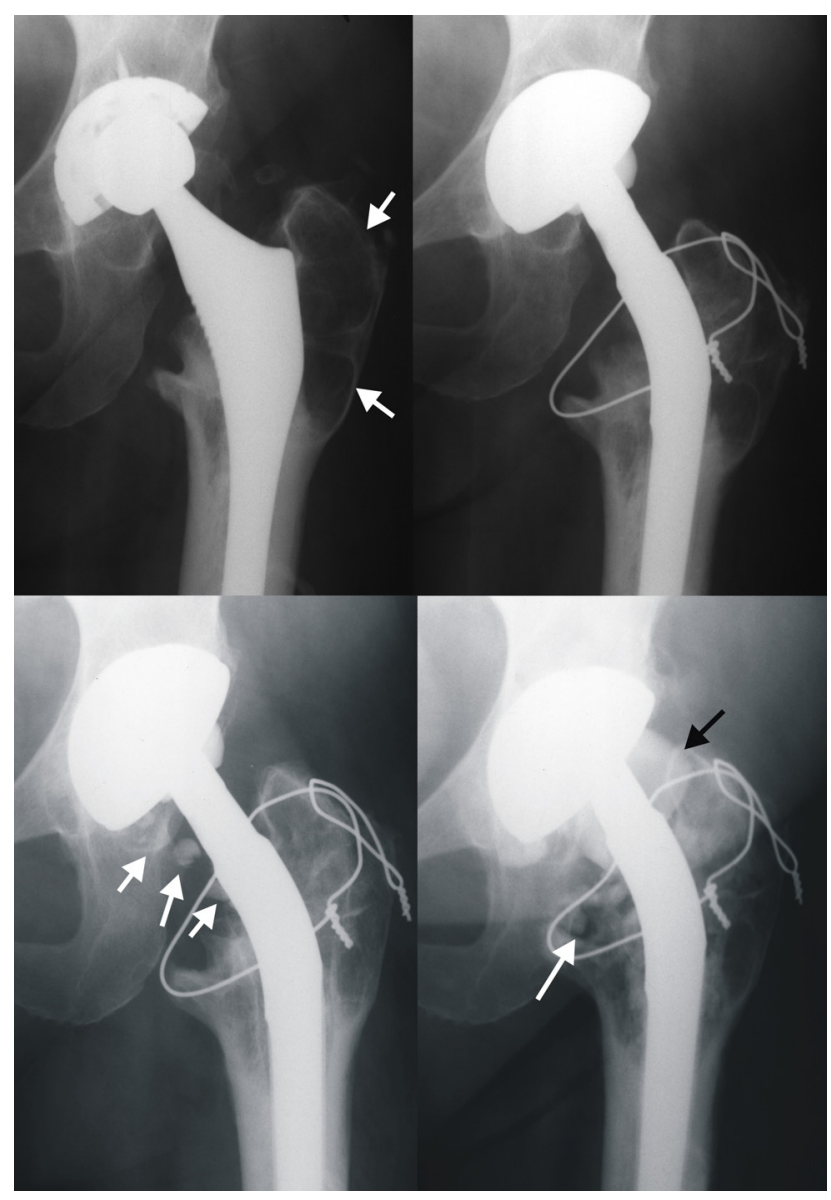

Fig. 1. A, Anteroposterior (AP) radiograph of the left hip taken before revision surgery and showing retroacetabular and femoral osteolysis (arrows). $\mathrm{B}, \mathrm{AP}$ radiograph of the same hip postoperatively. C, AP radiograph taken 30 months later, demonstrating small pieces of ceramic dislodged from the shell (arrows). D, AP radiograph performed before the second revision and showing dislocated large piece of ceramic liner (black arrow) and many small ceramic pieces along the stem (white arrow).

ro-fractography analysis of the destroyed parts of the ceramic liner, it can be concluded that the primary fracture was initiated at the inner surface of the cup (Fig. 3B). A large part of the inner surface of the cup was damaged by wear, most likely due to third-body abrasion prior to catastrophic fracture of the cup. The wear damage initiated multiple cracks during the loading regime until 1 crack reached a critical size, resulting in catastrophic failure.

We propose several possible causes for the fracture. The first is the presence of a micro-defect (manufacturing imperfection) at the surface or subsurface of the ceramic material. The second is introduction of micro-damage intraoperatively during fixation of the liner to the metallic shell. The third is trapping of a $\mu \mathrm{m}$-sized, hard foreign body between the ceramic liner and the prosthetic ball, initiating wear. The location of impingement could not be identified due to severe damage and absence of large 


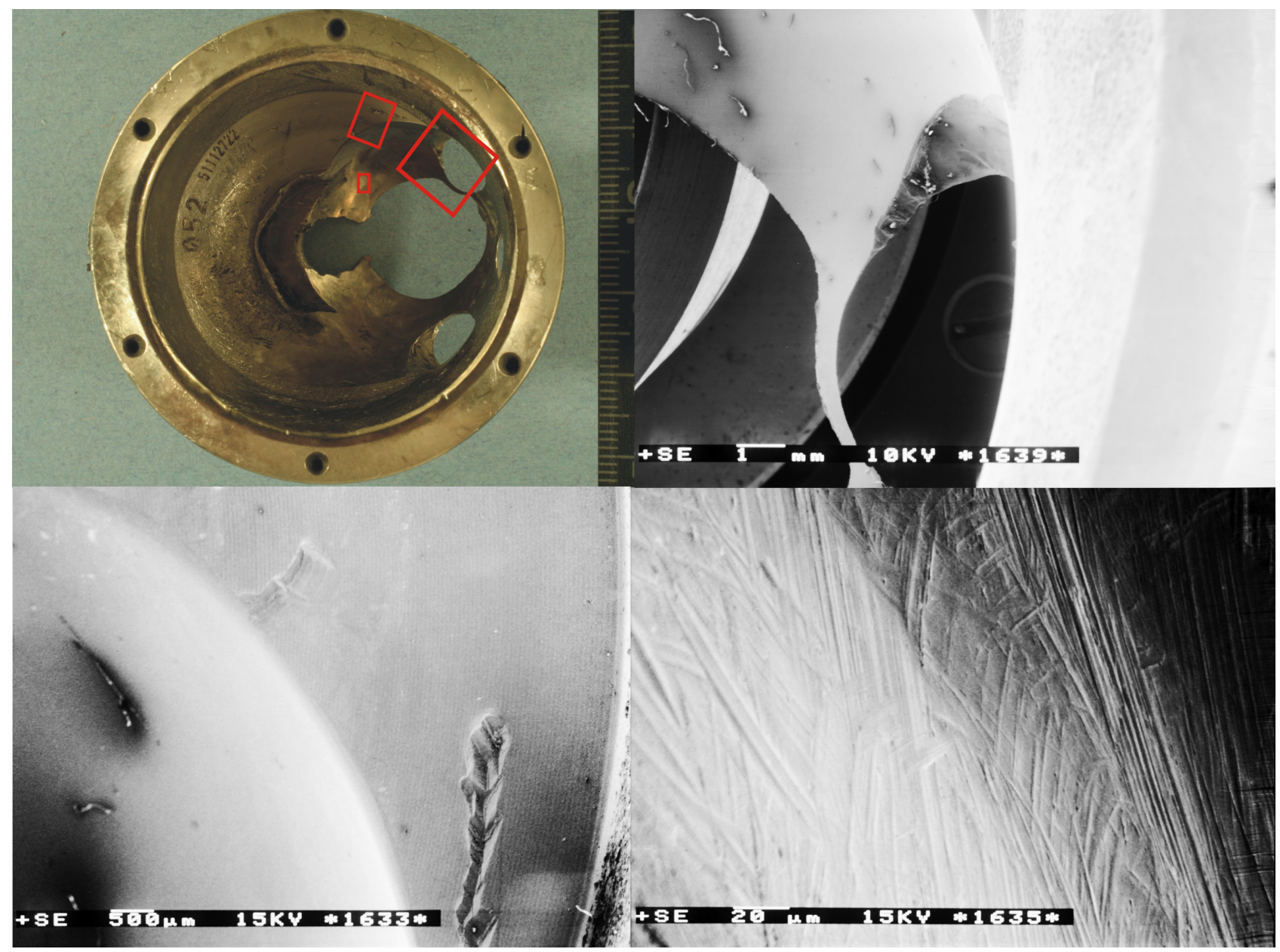

Fig. 2. A, A new cup created in the original metallic shell by the ceramic head after dislodgement of a large ceramic piece. B, Detail of the sharp ridge of the newly developed cup (big frame). SEM: scale bar $=1 \mathrm{~mm}$. C, Detail of the undamaged metallic shell (intermediate frame) with fine roughness on the original surface. The deep groove with an irregular edge was probably caused by a ceramic fragment. SEM: scale bar $=500 \mu \mathrm{m}$. D, Detail of the damaged surface (small frame) with a net of irregular striae probably caused by large ceramic debris. SEM: scale bar $=20 \mu \mathrm{m}$.

pieces of the ceramic liner rim. However, the neck of the stem may have repeatedly impinged on the rim of the acetabular cup until brittle fracture occurred at the protruding rim, producing a chip that then may have been trapped inside the bearing.

Improper positioning of the ceramic liner is another reported cause of fracture. Had the liner not been fully seated in the metallic shell, or had it been seated in an angular position, this may have resulted in high pointcontact stresses during normal gait ${ }^{10}$. Improper alignment and positioning of the shell can encourage rim contact referred to as stripe wear. Recent reports show that even well fixed and properly positioned acetabular components can exhibit this form of damage ${ }^{11}$. The stripe wear phenomenon is explained by micro-separation of the bearing centers during the swing phase of normal walking and subsequent edge loading on heel strike. Edge loading can cause a localized concentration of stress between the femoral head and the rim of the acetabular cup, leading to a characteristic stripe wear pattern. Postoperative causes of failure in such implants may be related to heavy falls, dislocations, or repetitive subluxations.

\section{DISCUSSION}

We describe the catastrophic failure of a Plasma cup SC ceramic liner in revision THA. Based on the patient's symptoms, it appears that the fracture occurred soon after surgery. This implies the presence of a defect originating in the manufacturing process or design, which was further propagated in response to intraoperative (heavier reduction of the hip) or early postoperative (subluxations or fall) events. In addition, the patient's high weight (body mass index $=31.8$ ) may have accelerated crack propagation.

There is a previously reported case of fracture of a Plasma cup ceramic liner in a 34-year-old man $(67 \mathrm{~kg}$, $164 \mathrm{~cm}$ ) from South Korea, 1 year and 9 months after surgery ${ }^{12}$. The fracture was probably caused by neck-rim 


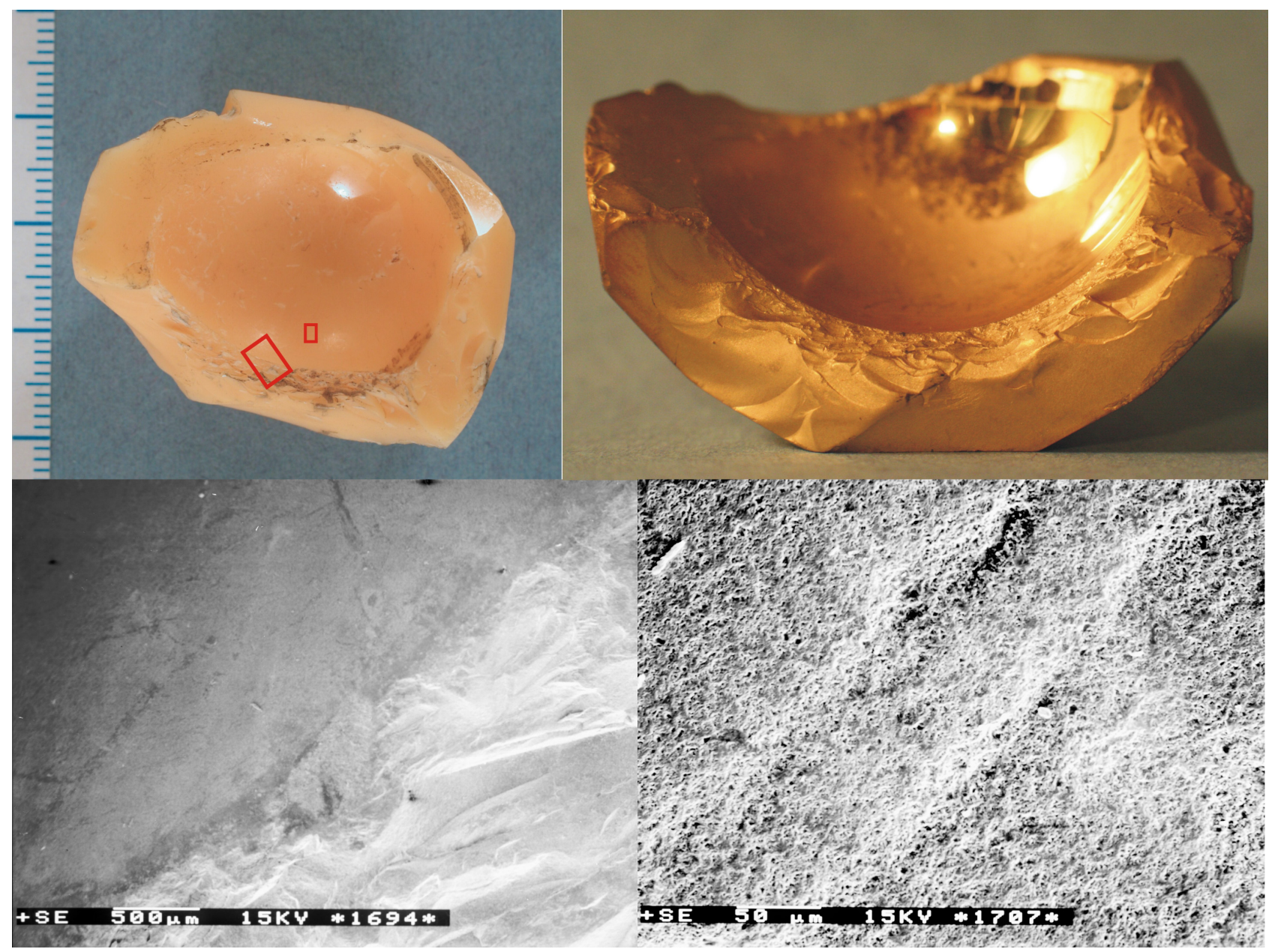

Fig. 3. A, Retrieved piece of ceramic liner with only a small area of preserved edge surface. B, View of the fracture surface. The fracture was probably initiated at the inner surface of the liner (big frame) and grew under the influence of a third-body abrasion wear mechanism. C, Detail of the interface between the fractured and unfractured surfaces of the retrieved portion of the ceramic liner. SEM: scale bar $=500 \mu \mathrm{m}$. D, An articulating surface of the ceramic liner (small frame) was damaged by ceramic wear. SEM: scale bar $=50 \mu \mathrm{m}$.

impingement due to extreme hip motions related to the daily activities of Asian people, who frequently squat or sit cross-legged. Evidence of contact between the femoral neck and acetabular rim was reported as a common feature on retrieved acetabular liners ${ }^{12,13}$. Although such extreme hip-joint motion is not likely in our case, stem-rim impingement cannot be completely excluded.

Intraoperative findings in our study were unlike those in the previous case report. Extensive metallosis was observed, compromising the bone bed due to both dissemination of hard ceramic fragments and direct wear of the metallic shell. In the Min et $\mathrm{al}^{12}$ report, the degree of damage to the ceramic inlay, shown in Figure 5 of their paper, was mild in comparison to that observed in our study. Earlier surgery would undoubtedly have diminished metallosis. The reasons for the delay were late diagnosis and patient-related factors.

To prevent catastrophic development, early and reliable diagnosis is needed. In our patient, the history of pain and feelings of subluxations continued from the pre-revision stage and were superimposed on the specific symptoms of ceramic liner fracture. In addition, other sources, including sepsis and extrinsic sources of hip pain, were investigated. This, together with late manifestation on radiographs, led to delayed diagnosis. Toni et $\mathrm{al}^{14}$ found a positive correlation between ceramic liner fracture and a noisy hip on clinical examination. They recommended computed tomography (CT) and joint aspiration in any snapping hip after ceramic THA to rule out early failure. However, we doubt that particle analysis of the joint aspirates is sufficiently widespread to enable routine examination. Also, if very early fracture occurs without dislocation of ceramic fragments, then the results of CT examination may be of limited value. Radiographic signs of fracture occurred late in our case. However, we suspect earlier fracture of the liner, since the ceramic pieces were contained within the metallic shell, their release being difficult ${ }^{15}$. Thus, awareness of that complication in conjunction with close follow-up may be of paramount importance during the early phase of ceramic THA failure.

The rate of ceramic liner fracture has been reported to be between $0 \%$ and $3.5 \%$, with a higher incidence 


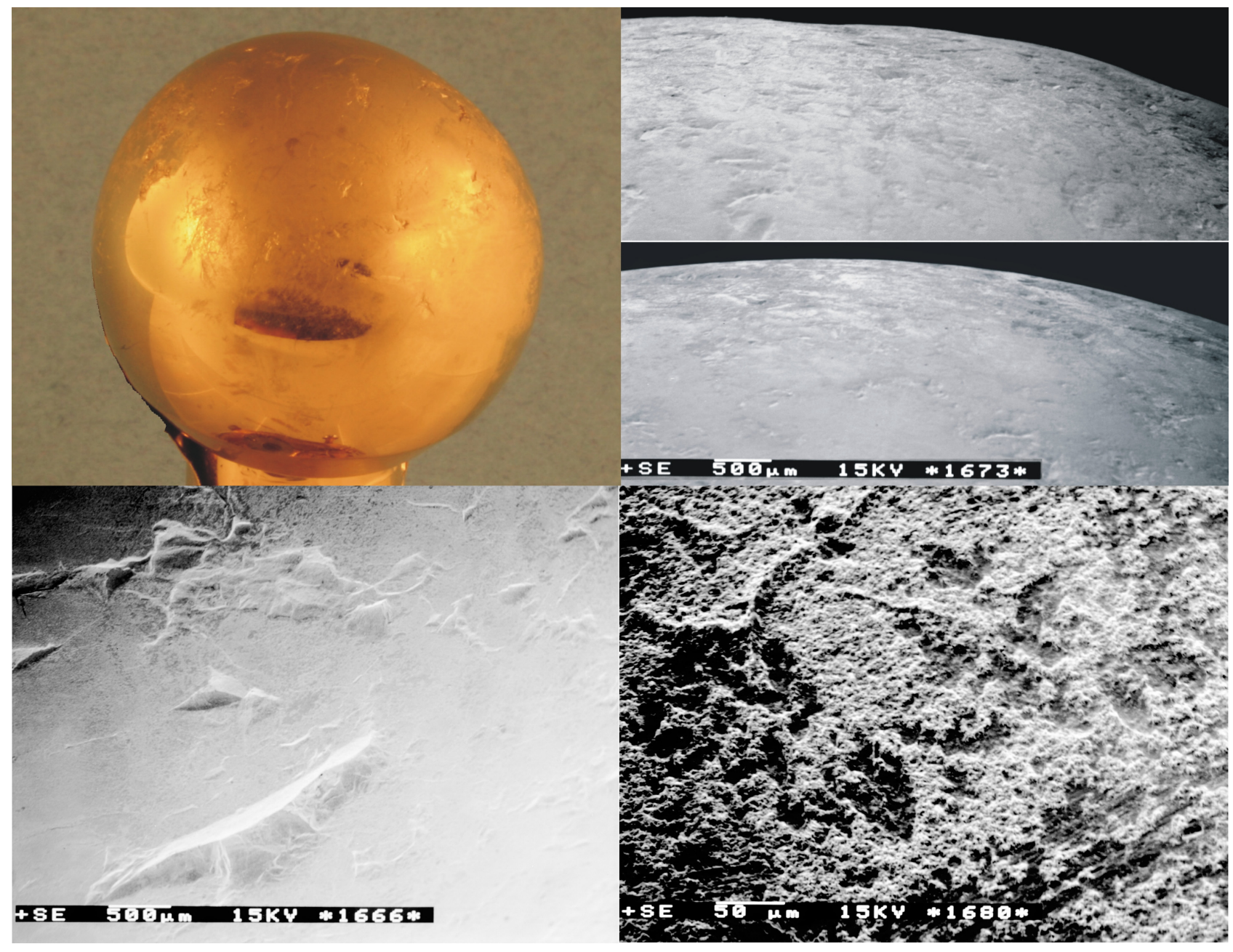

Fig. 4. A, Gold-coated ceramic ball before SEM investigation with an almost completely damaged surface and loss of ideal sphericity. B, Comparison of distinct regions of the surface of the prosthetic ball showing the wear damage. SEM: scale bar $=500 \mu \mathrm{m}$. C, The same area as in B but at a different viewing angle that illustrates the damage features after contact fatigue load. SEM: scale bar $=500 \mu \mathrm{m}$. D, Features of the damaged ceramic surface and damaged surface of the liner (Fig. 3D) are similar. SEM: scale bar $=50 \mu \mathrm{m}$.

among sandwich-type ceramic cups versus 1-piece components $^{3,13,16}$. Furthermore, the risk of fracture seems to be greater in the Asian population, where squatting, kneeling, and sitting cross-legged are more common than in the Western population. However, in the Western population, regardless of progress that has been made in optimizing the design of the insert and neck, impingement is also possible, especially with suboptimal implant positioning and in patients with a high range of motion ${ }^{4}$. Regarding the predisposition of alumina ceramic liners to fracture, an essential question remains: does this material easily fracture? Based on current quality requirements (FDA, ISO, etc.), experimental studies, and the rare rate of these events in clinical practice ${ }^{5,15,17,18}$, the answer seems to be no. The fracture strength of alumina ceramic liners was found to be more than $70 \mathrm{kN}^{19}$, and modern modular ceramic-on-ceramic hip arthroplasty can withstand a repetitive impact of up to $12 \mathrm{kN}^{15}$. But naturally, the hip is cyclically loaded with alternating phases of touch-down and separation during gait. In addition, the hip joint nor- mally transmits forces much lower than this, between 4.8 and $10 \mathrm{kN}$, depending on the method of measurement and the type of daily activities, including unwanted stumbling and falling ${ }^{20,21}$. As these values are far below the reported fracture threshold of modern ceramic liners, events such as fracture of a 1-piece ceramic liner should be interpreted as irregularities that might be explained as part of a range of pathological scenarios described in our case report. The likelihood for fracture under physiological conditions and precise operative techniques remains low.

\section{ACKNOWLEDGEMENT}

The study was supported by the grant of Ministry of Education, Youth and Sports of the Czech Republic No. MSM6198959223.

The authors wish to thank Tomas Procek, M.D. for his help with manuscript preparation. 


\section{REFERENCES}

1. Warashina H, Sakano S, Kitamura S, Yamauchi KI, Yamaguchi $\mathrm{J}$, Ishiguro $\mathrm{N}$, et al. Biological reaction to alumina, zirconia, titanium and polyethylene particles implanted onto murine calvaria Biomaterials 2003; 24:3655-3661.

2. Nizard R, Sedel L, Hannouche D, Hamadouche M, Bizot P. Alumina pairing in total hip replacement. J Bone Joint Surg Br 2005; 87:755-758.

3. Park YS, Hwang SK, Choy WS, Kim YS, Moon YW, Lim SJ Ceramic failure after total hip arthroplasty with an alumina-onalumina bearing. J Bone Joint Surg Am 2006; 88:780-787.

4. Barrack RL, Burak C, Skinner HB. Concerns about ceramics in THA. Clin Orthop Relat Res 2004; 429:73-79.

5. Sedel L, Raould A. Engineering aspect of alumina on alumina hip prosthesis. Proc Inst Mech Eng [H] 2007; 221:21-27.

6. Hannouche D, Nich C, Bizot P, Meunier A, Nizard R, Sedel L. Fractures of ceramic bearings: history and present status. Clin Orthop Relat Res 2003; 417:19-26.

7. Quitmann H, Wedemeyer C, von Knoch M, Russe K, Saxler G. Titanium serum levels may remain elevated despite hip revision surgery for wear-through of an acetabular component. Biomed Tech (Berl) 2006; 51:27-29.

8. Davis AM, Schemitsch EH, Gollish JD, Saleh KJ, Davey R, Kreder $\mathrm{HJ}$, et al. Classifying failed hip arthroplasty: generalizability of reliability and validity. Clin Orthop Relat Res 2003; 415:171-179.

9. Parvizi J, Ghanem E, Menashe S, Barrack RL, Bauer TW Periprosthetic infection: what are the diagnostic challenges? J Bone Joint Surg Am 2006; 88 (Suppl 4):138-147.

10. Anderson IA, Bowden M, Wyatt TP. Stress analysis of hemispherical ceramic hip prosthesis bearings. Med Eng Phys 2005; 27:115122.
11. Walter WL, Insley GM, Walter WK, Tuke MA. Edge loading in third generation alumina ceramic-on-ceramic bearings: stripe wear. J Arthroplasty 2004; 19:402-413.

12. Min BW, Song KS, Kang CH, Bae KC, Won YY, Lee KY. Delayed fracture of a ceramic insert with modern ceramic total hip replacement. J Arthroplasty 2007; 22:136-139.

13. Ha YC, Kim SY, Kim HJ, Yoo JJ, Koo KH. Ceramic Liner Fracture after Cementless Alumina-on-Alumina Total Hip Arthroplasty. Clin Orthop Relat Res 2006; 458:106-110.

14. Toni A, Traina F, Stea S, Sudanese A, Visentin M, Bordini B, et al. Early diagnosis of ceramic liner fracture. Guidelines based on a twelve-year clinical experience. J Bone Joint Surg Am 2006; 88 (Suppl 4):55-63.

15. Maher SA, Lipman JD, Curley LJ, Gilchrist M, Wright TM. Mechanical performance of ceramic acetabular liners under impact conditions. J Arthroplasty 2003; 18:936-941.

16. D'Antonio J, Capello W, Manley M, Naughton M, Sutton K. Alumina Ceramic Bearings for Total Hip Arthroplasty: Five-year Results of a Prospective Randomized Study. Clin Orthop Relat Res 2005; 436:164-171.

17. Hannouche D, Hamadouche M, Nizard R, Bizot P, Meunier A, Sedel L. Ceramics in total hip replacement. Clin Orthop Relat Res 2005; 430:62-71.

18. Pfaff HG. Ceramic component failure and the role of proof testing. Clin Orthop Relat Res 2000; 379:29-33.

19. Hasegawa M, Sudo A, Hirata H, Uchida A. Ceramic acetabular liner fracture in total hip arthroplasty with a ceramic sandwich cup. J Arthroplasty 2003; 18:658-661.

20. Bergmann G, Deuretzbacher G, Heller M, Graichen F, Rohlmann A, Strauss J, et al. Hip contact forces and gait patterns from routine activities. J Biomech 2001; 34:859-871.

21. van den Kroonenberg AJ, Hayes WC, McMahon TA. Hip impact velocities and body configurations for voluntary falls from standing height. J Biomech 1996; 29:807-811. 